Economía, Sociedad y Territorio, vol. vIII, núm. 26, 2008, 561-564

\title{
Dos visiones en debate
}

\author{
Cherem, Silvia S., (2006), Examen Final: LA EDUCACIÓN \\ en MÉXICO (2000-2006), 2 tomos, CREFAL-El Equilibrista, \\ MÉXICO, 707 PP. ISBN I: 968-5011-71-0, II: 968-5011-72-9
}

\section{La visión optimista}

El tomo I de la obra de Silvia Cherem nos lleva por una profunda entrevista con quien fue secretario de Educación Pública en México, Reyes Tamez Guerra, durante el sexenio 2000-2006.

La entrevista que logra Silvia Cherem -y sin ánimo de minimizar el esfuerzo de la periodista-, en algunos momentos carece del rigor deseado por algunos (me cuento entre ellos) para desentrañar aún más la evidente situación de deterioro y atraso en que se encuentra el sistema educativo mexicano.

La lectura es ágil y, en ciertos momentos, amena. Silvia Cherem nos lleva de forma sencilla a conocer el currículo profesional y académico de un funcionario del gobierno del cambio, reclutado por un equipo de head hunters (cazadores de talentos), como él mismo lo manifiesta. Tamez Guerra relata sus actividades como líder estudiantil, su época de estudiante de posgrado en la Universidad Autónoma de Nuevo León (UANL) y el Instituto Politécnico Nacional (IPN) hasta su experiencia como rector de la UANL, antes de ser seleccionado secretario de Estado. Resulta interesante analizar la trayectoria profesional y académica de un personaje que dirigió el destino de la educación en México, ya que, en sexenios anteriores, la experiencia laboral y la preparación académica eran características desconocidas de los miembros del gabinete.

La inexperiencia de Reyes Tamez en asuntos de educación (sobre todo en los niveles básico y medio) y políticas educativas marcaron el derrotero de su gestión como secretario de Educación Pública, al frente de una de las instituciones más difíciles de administrar por la naturaleza de su propósito y los actores que la conforman, entre ellos el Sindicato Nacional de Trabajadores de la Educación (SNTE) y la Coordinadora Nacional de Trabajadores 
de la Educación (CNTE). Reyes Tamez emprende y logra poner en marcha de forma parcial tres programas que hacen énfasis en la calidad educativa: el Programa Nacional de Lectura (PNL), el Programa Enciclomedia y el Programa Escuelas de Calidad (PEC), los cuales en el corto plazo se convertirían en punta de lanza del gobierno de Vicente Fox.

Acerca del rezago educativo, la posición de Reyes Tamez es clara, convencido de la efectividad de los programas educativos, su discurso se vuelve predecible, repetitivo y sin contenido, argumentando desde diferentes puntos de vista las bondades y ventajas de las acciones emprendidas. Lo anterior no quiere decir que quien esto escribe esté en contra, pues existen elementos de gran riqueza en las propuestas que estructuradas y llevadas a cabo de forma diferente, podrían colaborar en la resolución de problemas educativos desde el punto de vista operativo.

En relación con el SNTE, toma distancia y argumenta que no existió conflicto alguno. Esto podría ser verosímil si no existiera el antecedente corporativista del mayor sindicato de México. Renuente a responder las preguntas en materia de políticas públicas y toma de decisiones en la SEP. Se manifestó como una persona respetuosa y comprometida en todos los actos y acuerdos entre la Secretaría de Educación Pública (SEP) y el SNTE.

\section{La visión crítica: la voz de los expertos}

En contraste con Reyes Tamez, en el segundo volumen los expertos en educación no comparten su optimismo en relación con la crisis que atraviesa el sistema educativo. Los problemas son de índole diferente y se presentan en los tres niveles de educación. Además de lo anterior, al fenómeno se suman las dificultades que traen consigo los nuevos programas educativos dirigidos al nivel básico, que se relacionan con la ejecución, cobertura, operación y capacitación de los profesores. El nivel medio continúa desatendido y estancado mientras que las instituciones de educación superior continúan en su lucha por mantener su autonomía.

Los diagnósticos y las críticas no se dejan esperar, de acuerdo con la opinión de los expertos: la crisis educativa se encuentra en su punto más álgido. Las opiniones de éstos se enfocan en diversos aspectos de la problemática y atenderlas sería el punto de partida para una posible solución a las múltiples dificultades. Los problemas son de antaño, se dejaron a la deriva por razones políticas, operativas, administrativas, o simplemente por falta de voluntad. 
Los especialistas coinciden en varios aspectos, entre ellos, educación para todos y de calidad; al parecer ya se dio el primer paso, pero hace falta más que una computadora en el aula para que sea de calidad. ¿Más cobertura? Sí, pero bajo qué condiciones. ¿Evaluación? Totalmente de acuerdo, pero con qué mecanismos y criterios, ¿̇los de la Organización para la Cooperación y el Desarrollo Económico (OCDE) y la Organización para la Educación, la Ciencia y la Cultura (UNESCO)?, o deberíamos empezar a crear los nuestros, basados en las características sociales, psicológicas y culturales de nuestros niños y jóvenes, además de aspectos económicos y políticos del país. ¿Se necesitan más bibliotecas? Sí, pero quién las opera y en qué condiciones. ¿Qué tipo de libros deben leer los estudiantes?

¿Escuelas laicas? Al parecer esta fue y es la pregunta de los gobiernos de derecha, la respuesta es sencilla: sí, y Carlos Monsiváis tiene argumentos sólidos para soportarla. Por supuesto se respeta el derecho de cada individuo de profesar la religión o culto que más le convenga. El federalismo se convierte también en asunto prioritario, el gigante burocrático ya no puede más. Es necesario dar autonomía a los estados en materia educativa para atender sus necesidades de forma eficiente y eficaz, sin tener que esperar el mandato de los altos directivos de la SEP y del SNTE.

Por todos es conocido que la hegemonía del SNTE en materia de asuntos educativos ha sido el mayor lastre en el desarrollo de una educación de calidad. El corporativismo sentó sus bases y al parecer la tarea de sanear el sindicato y ponerlo a hacer lo conducente no es prioridad en la agenda educativa de los gobiernos panistas. Carlos Ornelas da un escenario preciso de la participación del SNTE en el desarrollo educativo, desde su fundación hasta la época del liderazgo de Elba Esther Gordillo.

Universidades 'patito', aspectos culturales, democratización de la educación, más capacitación del magisterio y de los docentes en los niveles medio y superior, disminución de la nómina del magisterio y más inversión en materia operativa, así como la puesta en marcha de programas de calidad, también son puntos relevantes y que están en el foro del debate de uno de los aspectos más importantes en el desarrollo de un país: educación. 
Recibido: 6 de julio de 2007. Aceptado: 6 de julio de 2007.

RicARDo ÁNGELES EsCOBAR Colegio Nacional de Educación Profesional Técnica correo-e: trexraven@prodigy.net.mx

Ricardo Ángeles Escobar. Es licenciado en administración por la Universidad Autónoma Metropolitana. Actualmente realiza estudios de maestría en desarrollo y planeación de la educación en la misma institución. Su línea de investigación actual es el binomio escuela-trabajo. Es profesor de tiempo completo en el Colegio Nacional de Educación Profesional Técnica (Conalep) donde imparte materias de administración. 